\title{
A NEW TWO-STAGE NURSE SCHEDULING APPROACH BASED ON OCCUPATIONAL JUSTICE CONSIDERING ASSURANCE ATTENDANCE IN WORKS SHIFTS BY USING Z-NUMBER METHOD: A REAL CASE STUDY
}

\author{
Mohammad Javad Pahlevanzadeh ${ }^{1}$, Fariborz Jolai ${ }^{1}$, Fariba Goodarzian ${ }^{1,2, *}$ \\ AND PEIMAN GHASEMI ${ }^{3}$
}

\begin{abstract}
In this paper, a new binary integer programming mathematical model for scheduling nurses' problems in the emergency department of Kamkar Hospital in Qom province is developed. The manual arrangement of nurses by the head nurse and its time-consuming, occasional absences during the period and protests against injustices in the arrangement of nurses' work shifts were among the emergency department's challenges before implementing the model. Most relevant studies aimed to enhance nurses' satisfaction by creating a general balance considering occupational preferences. Thus, the present study pursued justice through considering preferences based on the results from periodical evaluations of each nurse's performance with the ultimate goal of improving nurses' satisfaction. Moreover, the lack of clarity in selecting shifts, which may cause irregular attendance, was improved using the Z-number method. After the run of the model, the rate of nurses' absences decreased by $40 \%$, the rate of complaints about the performance of the nursing unit decreased by $50 \%$. Also, nurses' satisfaction increased by $30 \%$ after the implementation of the model.
\end{abstract}

Received June 12, 2021. Accepted October 13, 2021.

\section{INTRODUCTION}

Nurse Scheduling (NS) refers to shift design for each nurse in compliance with the regulations and policies or other health facilities. Hospital nurses work around the clock, typically divided into three to four shifts. The emergency unit is one of the essential hospital departments. This study addressed nurse scheduling in the hospital's emergency unit.

One of the significant challenges facing healthcare service providers is the efficient assignment and management of resources $[8,54]$. Nursing staff management is challenging because it is done at various organizational levels and temporal horizons ([31]). Low nursing service quality causes irreparable effects on the patients,

Keywords. Scheduling problem, occupational justice, nurses satisfaction enhancement, Z-number method.

1 School of Industrial Engineering, College of Engineering, University of Tehran, Tehran, Iran.

2 Machine Intelligence Research Labs (MIR Labs), Scientific Network for Innovation and Research Excellence, 11, 3rd Street NW, P.O. Box 2259, Auburn, WA 98071, USA.

3 Department of Industrial Engineering, South Tehran Branch, Islamic Azad University, Tehran, Iran.

*Corresponding author: fariba.goodarzian@mirlabs.org

(c) The authors. Published by EDP Sciences, ROADEF, SMAI 2021 
including mortality [34]. Medical personnel's performance has a significant impact on the quality of public health care ([45]). Proper scheduling of nurses increases their productivity ([10], Blythe and Goodpasture [9]).

Different staff scheduling solutions, including nurse scheduling, have been developed [14]. Many of these scheduling solutions consider nurses' preferences while complying with hospital regulations [48,49]. An important matter in setting nurses' preferences is justice in the assignment of shifts and days off. The present study investigated the specific conditions and policies of the Kamkar Hospital of Qom and the nurses' concerns using in-person interviews.

Contrary to previous studies, the present study tried to establish the concept of occupational justice among nurses directly based on each nurse's performance on the shifts, thereby increasing their performance and motivation. Another essential matter is uncertainty in practicing nurses' preferences in actual conditions. Nurses' opinions about their work preferences and day-offs for the next 28 days are gathered at the beginning of each period; however, these preferences are not definitive and, in most cases, are accompanied by some problems, such as emergency absences, because of uncertainty. This problem was partially solved by ensuring attendance at work shifts based on the Z-number method, and accidental absences were reduced.

Therefore, with increasing healthcare services in public and private hospitals, the patients have become more aware of appropriate services. Their satisfaction has become a challenge facing the health sector [28]. Then, the points mentioned above highlight nurses' undeniable importance in the health system. Appropriate nurse scheduling increases nurses' productivity [10]. Moreover, nurses' appropriate assignment results in the more effective use of resources, higher income, and finally, enhancement of patients' satisfaction [22].

The level of confidence of each nurse in choosing work shifts is an issue that affects the stability of the model and causes possible irregularities and accidental absences. In this paper, each nurse's preferences were considered in the form of a Z-number to improve this problem. Thus, in addition to each nurse's possibility of being present in the relevant shift, his confidence in the selected shift is also questioned. In addition to considering the possibility of each nurse being present in the relevant shift, her confidence in the selected shift is also questioned. Thus, in the second objective function, it is tried to select shifts that ensure the presence of people in that shift is higher. In addition, by using the model's limitations, the nurse's assignment to a shift that ensures its presence in the relevant shift is less than the value of the parameter $\mu$ is avoided. Accordingly, nurses' preferences are received as zero and one for each shift during the course. The first objective function tries to increase nurses' satisfaction by applying their preferences. One of our main challenges was interviewing each nurse and receiving preferences, and ensuring their presence in work shifts during the 28 days.

Therefore, after the interview and completing the questionnaire for each nurse, their preference and level of confidence to attend each shift have been determined. In addition, another of our challenges was ranking nurses and using each individual's ranking coefficients to apply preferences in the first objective function. We also first collected information about nurses' performance appraisals during one period and then used this information to schedule work shifts in the next period.

The rest of the paper is organized as follows. In the second section, the studied research in the presented field is stated. The third and fourth sections examine problem description, mathematical modeling, and research methods. In the fifth and sixth sections, the implementation results and analysis of the sensitivity of the proposed model are evaluated. Finally, the conclusion and future works will be examined.

\section{BACKGROUND OF STUdY}

Studies have proposed various definitions for staff scheduling, including nurse scheduling. Burke and Soubeiga [11] defined staff scheduling as assigning the right staff to the correct positions at the right time to achieve the internal and external organizational goals. In other words, staff scheduling was the process of the assignment of limited resources over time to achieve a balance between staff requirements and their duties [39]. Demand, internal rules, external rules, and quality dimensions are four elements to be considered in regulating an effective and efficient program [20]. Despite many studies on nurse scheduling, it is done manually in many hospitals. 
Among these manual methods are the periodical and rotational methods. The introduction of operational research in health dates back to 1950 [24].

Many studies have been conducted on nurse scheduling since 1970. Maier-Rothe and Wolfe [32] were two pioneers in studying this field. A nurse was assigned only one shift per day in their nurse scheduling solution. The aim was to minimize the total number of nurses. Alharbi [4] tried to maximize nurses' preferences by implementing a mathematical model. In this model, annual holidays, weekends, and other nurses' preferences were considered. Guo et al. [19] first obtained the number of patients (demands) using the time series model and then obtained the required number of nurses. They planned a new shift for one week for ten head nurses, ten senior nurses, and six ordinary nurses. They also obtained the demand through the queuing theory and based on patients' waiting time. The algorithm proposed can dynamically arrange the nurses' desired shifts and effectively manage patients' waiting times. It was also revealed that varying shift times could affect nurses' productivity and job satisfaction [36,38] and negatively affect them [44]. As a result, to reduce these adverse effects, various approaches (e.g., fuzzy approach) and models have been developed to solve the nurse scheduling problem mentioned below [43]. The improvement of equity and justice in nurse shifts can be observed [23]. They used the metaheuristic algorithm of SSP to solve the model. The results showed that this algorithm was faster and more flexible than particle swarm optimization.

Zanda et al. [53] performed a long-term (i.e., one year) nurse scheduling in the Surgery Unit of the Cagliari Hospital, Italy, proposing a decision-making support system. They used a linear integer programming approach with some one-month sub-periods. In their model, nurse transfer from other units was acceptable in demand coverage but did not correspond to penalty. Mohammadian et al. [35] used a goal programming approach for nurse scheduling in the Emergency Unit of the Baqiyatallah Hospital in Tehran. They scheduled 28 days for 27 nurses.

In the relevant model, seven goals were considered at the end of the solution, three ideals (share, order, and isolation of work shifts) in total. Four ideas, including nurses' satisfaction, number of working days, days off, and limited resources, are considered. The results showed that scheduling had increased work fairness and improved nurses' performance and satisfaction. Additionally, the nurses were scheduled in the probability space using dynamic planning and combining the branch and price algorithms with the matching neighborhood search algorithm by Legrain et al. [29]. In their model, the primary-secondary algorithm-generated candidate programs for the current week and the sample average approximation algorithm selected the best-generated programs. Numerical results showed that their algorithm could perform well for 4-8 weeks and up to 120 nurses. They recruited 120 nurses for four shifts of 8 weeks. One of their innovations was considering each nurse with specific requirements (such as contract type, preferences, and skill level). They also considered many of the restrictions (such as the number of nurses required for each shift and their preferences) in the form of soft restrictions (with fines for exceeding the allowable limit).

Svirsko et al. [47] presented how to plan their paradigm. In fact, unlike a manager or decision planner as to who works at what time, the responsibility of creating the group's program will be assigned to the nurses themselves. Instead of having a manager or schedule to decide who works at what time, the shifts available to the nurses selected and exchanged are combined with mathematical modeling. They set the $8 \mathrm{~h}$ and $12 \mathrm{~h}$ blocks to deliver the nurses' timing. In their model, each nurse on every shift could have time to meal without problems. They were aimed at making minor changes in the planned blocks.

Hamid et al. [21] considered human factors such as skill, preference, and adaptation, nurses scheduled nurses in Tehran hospitals. Their goals include minimizing total staff costs, minimizing inconsistencies between nurses' decisions to be on the same work shift, and maximizing the total nurses' preference. They used the three metaheuristic algorithms to solve their model, including multi-objective Keshtel algorithm, non-dominated sorting genetic algorithm II, and multi-objective Tabu search. The data envelopment analysis method was also used to rank Pareto solutions. Implementing the proposed program improved the job satisfaction and human errors of nurses. Schoenfelder et al. [42] developed a new approach and presenting a possible multi-stage model. They scheduled the nurses. Their goal was to reduce patient response time, manage patient demand fluctuations, and ultimately improve hospital performance. They looked at information from three hospitals 
in the United States. They concluded that a combination of using multi-skilled nurses and transferring some patients to similar wards could lead to better performance. Their model increased hospital costs in the planning phase but improved hospital performance. Uhde et al. [50] investigated the concept of justice between shifts and the mechanisms of practicing it. Their findings showed that nurses' occupational equity is not equal to justice; instead, achieving justice needs more endeavors.

Fathollahi-Fard et al. [17] proposed bi-objective home healthcare for scheduling and routing problems based on uncertain patients' satisfaction. They provided two objectives, including minimizing the total costs and maximizing the patients' satisfaction. Additionally, they developed a new algorithm called adaptive memory social engineering optimization (AMSEO) and utilized simulated annealing and NSGA-II algorithms to solve their model. Goodarzian et al. [18] developed a bi-objective home healthcare network considering route balancing and working time. They considered two objectives, including minimizing the total costs and the total service time. Also, they used several meta-heuristic algorithms to solve their model, including the firefly algorithm, artificial bee colony algorithm, and social engineering optimization algorithm. In addition, they developed a new algorithm called improved social engineering optimization (ISEO) for the first time. Amindoust et al. [5], considering the fatigue factor in nurses, scheduled the nurses in the hospitalization ward of 19 patients in 19 hospitals in Isfahan province in Iran. Their goal was to schedule nurses to minimize fatigue from patient care in the event of a Covid 19 pandemic. They used a hybrid Genetic Algorithm (GA) to solve the model, which showed that the situation was better than before planning.

Jafari et al. [26] presented a two-objective model and took into account the preferences of nurses in a fuzzy way, scheduled nurses. Their goal was to maximize nurses' preferences for work shifts as well as weekends. Also, they presented uncertainties in worshipers' preferences using fuzzy modeling based on Werner's fuzzy approach.

Nasir et al. [37] represented a rotational periodic scheduling model by using ideal planning. Their study was performed on nurses in the CCU ward of Shah Alam Hospital in Malaysia, that the model provided a fair schedule for 15 nurses in 15 days. Also, the pattern was then rotated among all nurses for 225 days. Also, Ariyani et al. [6], obtained the optimal number of nurses required for each work shift using ideal planning and solving it with Lingo software.

Many factors affect nurses' job satisfaction, including organization and nurse shifts, as essential factors [40]. One of the most critical issues in nurse scheduling is paying attention to nurses' needs, demands, and preferences in general. Paying attention to nurses' preferences directly affects their satisfaction and productivity. The nursing staff's suitable performance directly affects the enhancement of hospital productivity and patient satisfaction $[3]$.

Researchers have used similar methods to increase nurses' satisfaction and apply their opinion. Including considering the preferences of nurses as general equality for all $[4,15,35]$, balancing and equalizing working hours [2], equality of the number of work shifts, and shutdown shifts $[13,29,30]$.

Our approach in this study is to apply nurses' preferences for working days and holidays based on justice. Based on the higher rank of each nurse, more attention is paid to her experiences. Each nurse gets a specific rank based on the evaluation of the previous period's performance based on the higher rank of each nurse, and more attention is paid to her experiences. In this way, unlike previous research, justice makes sense instead of equality.

In this study, a two-step approach has been used to schedule nurses in the emergency department of Kamkar Hospital in Qom province. In the first stage, using expert opinions and previous research in evaluating the performance of nurses, we have collected indicators related to the ranking of nurses. Using the fuzzy TOPSIS method and periodic information, nurses are ranked based on their monthly performance. Also, the nurses' confidence in the selected shifts based on the Z-number method is received at this stage. Z-number has been used in this study to obtain the reliability of these numbers in addition to nurses' preferences. In fact, in addition to expressing their opinion better, each nurse can express his/her opinion. Finally, reliability can be considered one of the model's essential inputs. Therefore, it can be concluded that by considering reliability as an input, the reliability of the results increases and can be more useful in natural environments. By reviewing the research 
done in this section and the explanations given in the previous section, including the contributions of this paper, the following can be mentioned:

- Applying nurses' preferences based on the ranking obtained from performance appraisal.

- Considering ensuring attendance at work shifts based on the Z-number method.

- Using scheduling nurses' work shifts based on justice.

- Suggesting a real case study to validate the proposed model.

\section{Problem Description}

In this study, we scheduled nurses' work shifts in the emergency department of Kamkar Hospital in Qom province. The hospital has a kindergarten where some female nurses take their children to the kindergarten during work shifts. The capacity of the kindergarten for nurses in various departments, including the emergency department, is known and limited. Also, according to the hospital rules, some work shifts require at least a certain number of female nurses. Therefore, according to the existing structure, we considered nurses in three categories: men $(i)$, women without children $(j)$, and women with children $(k)$. Work shifts are in three shifts: morning, evening, and night; according to the hospital rules, the calculated working hours are 6-6-19. During the conversations with the nursing unit and me nurses, the following vital problems in the nurses' scheduling process were identified:

- Manual arrangement of nurses and the time-consuming process for scheduling the nursing unit.

- Lack of transparency in the type of nurses' arrangement in different shifts.

- Nurse's protest and satisfaction reduction for not observing justice.

- Numerous unplanned absences of nurses during the course.

According to the above, we first ranked the nurses based on their performance in the previous period. The criteria for ranking were done through interviews with experts and also using past research. Then, the criteria were weighted through the hierarchical analysis technique, and ranking was done through the fuzzy TOPSIS technique. Thus, the rank of each nurse was obtained $\left(p_{i}, p_{j}, p_{k}\right)$. In addition to considering the possibility of each nurse being present in the relevant shift, their confidence in the selected shift is also questioned.

The second step introduced the hospital's policies and rules as a constraint in the relevant mathematical model. Restrictions such as:

- Prohibition of three consecutive night shifts.

- Prohibition of consecutive night and morning shifts.

- Minimum and maximum total working hours allowed during the course for each nurse.

- Maximum number of nurses allowed with children to be accommodated in each shift (based on the kindergarten capacity for the emergency department).

- The minimum acceptable confidence level for shift assignment.

The parameter $\mu$ is determined by the head nurse. This parameter indicates the minimum and maximum acceptable level of confidence (from zero to one hundred percent) for placement in work shifts. In our model $\mu$ was considered equal to $50 \%$. The level of confidence of each nurse to be in various work shifts $\left(S_{i d l}, O_{j d l}, T_{k d l}\right)$ is obtained from each nurse through a questionnaire based on the Z-number method.

For example, if the $i$ th nurse confidence level for a work shift $l$ on day $d$ is $0.4\left(S_{i d l}=0.4\right)$, constraint (3.22) does not allow the nurse to be hired for the shift. Also, the preferences (favorable and unfavorable) of the nurses for being in various work shifts $\left(f_{i d l}, f_{j d l}, f_{k d l}\right)$ were obtained through a questionnaire in the form of zero and one. The number one indicates the willingness, and the zero indicates the nurse's unwillingness to work shifts.

The first objective function of the problem seeks to increase the satisfaction of nurses by applying preferences (favorable and undesirable) based on the rank of each nurse. The higher the rank of a nurse, the higher will be the application of his preferences. $\pi_{1}$ and undesirable preferences with weight $\pi_{2}$. These weights are between zero and one, and their sum is equal. In our model, based on the opinion of the head nurse, both were equal 
to 0.5 . The second objective function seeks to select shifts where the nurse is more confident of attending those shifts. Thus, by presenting these innovations, we could solve the emergency department's fundamental problems in scheduling nurses' work shifts to a large extent and increase nurses' satisfaction.

The model assumptions are as follows:

- The weight of undesired and desired preferences is determined.

- The capacity of kindergarten is determined.

- The shifts are considered as morning, evening and night.

- Female nurses are divided into two types with child and without child.

\subsection{Parameters}

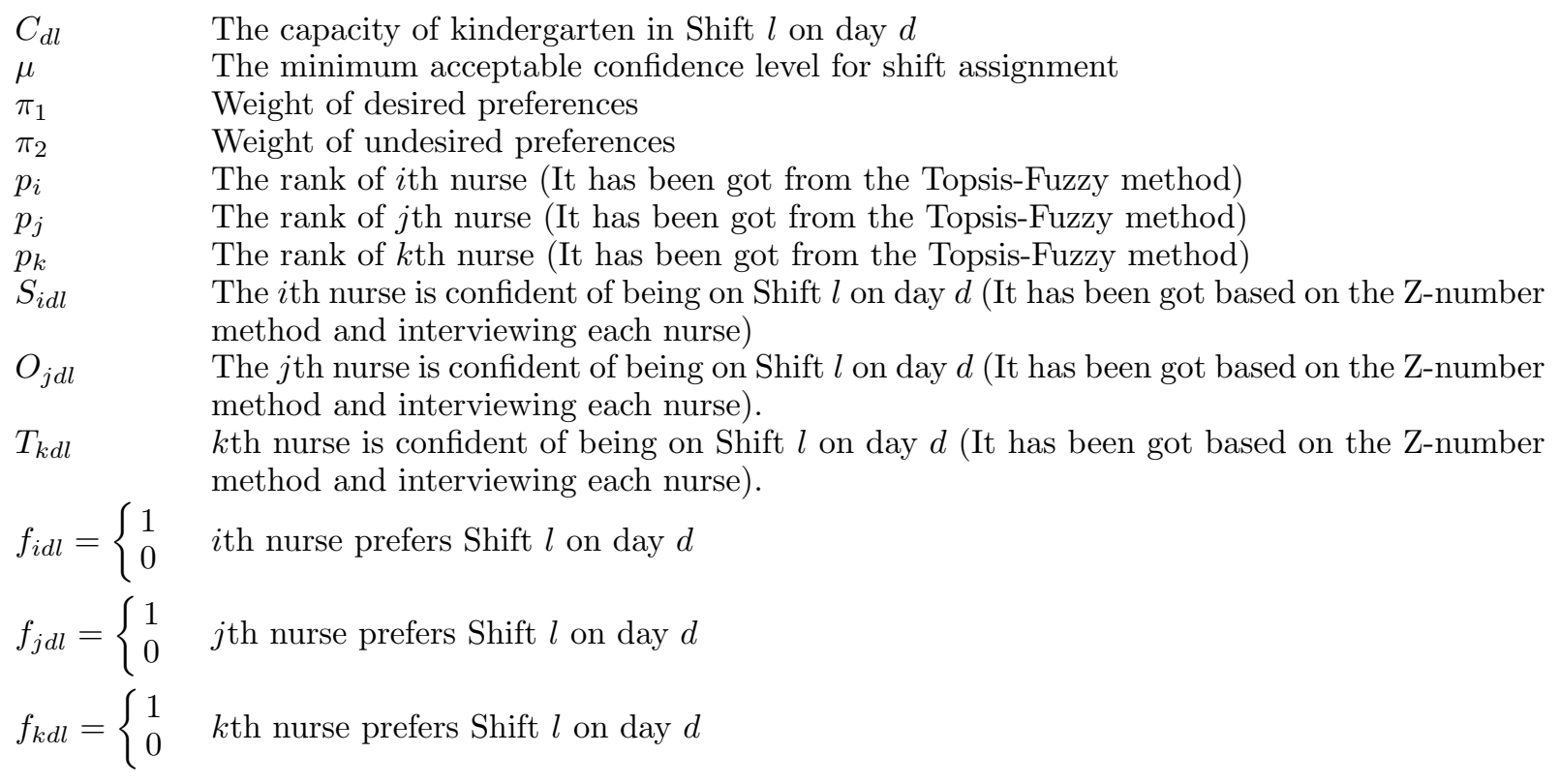

\subsection{Decision variables}
$X_{i d l}=\left\{\begin{array}{l}0 \\ 1\end{array}\right.$
It is one if the $i$ th nurse is on Shift $l$ on Day $d$; otherwise, it is 0
$Y_{j d l}=\left\{\begin{array}{l}0 \\ 1\end{array} \quad\right.$ It is one if the $j$ th nurse is on Shift $l$ on Day $d$; otherwise, it is 0
$Z_{k d l}=\left\{\begin{array}{l}0 \\ 1\end{array}\right.$ It is one if the $k$ th nurse is on Shift $l$ on Day $d$; otherwise, it is 0

\subsection{Mathematical model}

\subsubsection{Indices}

$i=1,2,3, \ldots, I \quad$ Male nurse

$j=1,2,3, \ldots, J \quad$ Female nurse without a child

$k=1,2,3, \ldots, K \quad$ Female nurse with a child

$d=1,2,3, \ldots, D \quad$ Working days

$l=m, e, n \quad$ Morning, evening, and night shifts

$\operatorname{maximize} Z_{1}=\pi_{1}\left[\sum_{i} \sum_{d} \sum_{l} F_{i d l} \times p_{i} \times X_{i d l}+\sum_{j} \sum_{d} \sum_{l} F_{j d L} \times p_{j} \times Y_{j d L}+\sum_{k} \sum_{d} \sum_{l} F_{k d l} \times p_{k} \times Z_{k d l}\right]$ 


$$
\begin{aligned}
& +\pi_{2}\left[\sum_{i} \sum_{d} \sum_{l}\left(1-F_{i d l}\right) \times\left(-p_{i}\right) \times X_{i d l}+\sum_{j} \sum_{d} \sum_{l}\left(1-F_{j d l}\right) \times\left(-p_{j}\right) \times Y_{j d l}\right. \\
& \left.+\sum_{k} \sum_{d} \sum_{l}\left(1-F_{k d l}\right) \times\left(-p_{k}\right) \times Z_{k d l}\right] .
\end{aligned}
$$

Equation (3.1), representing the first objective function, aims to demonstrate desired and undesired nurses' preferences obtained from their performance evaluation. In this equation, the importance of desired and undesired preferences can be changed by altering coefficients of $\pi_{1}, \pi_{2}$.

$$
\text { maximize } Z_{2}=\sum_{i} \sum_{d} \sum_{l} S_{i d l} \times X_{i d l}+\sum_{j} \sum_{d} \sum_{l} O_{j d L} \times Y_{j d L}+\sum_{k} \sum_{d} \sum_{l} t_{k d L} \times Z_{k d l} .
$$

Equation (3.2) represents the second objective function. This equation seeks to improve the model's certainty based on the selected shifts and reduce chaos during the period.

$$
\begin{aligned}
& \left(X_{i, d+1, m}+X_{i, d, n}\right) \leq 1 \\
& \forall i, d, m \\
& \left(Y_{j, d+1, m}+Y_{j, d, n}\right) \leq 1 \\
& \forall j, d, m, n \\
& \left(Z_{k, d+1, m}+Z_{k, d, n}\right) \leq 1 \\
& \forall k, d, m, n \\
& \left(X_{i, d, n}+X_{i, d+1, n}+X_{i, d+2, n}\right) \leq 2 \\
& \forall i, d, n \\
& \left(Y_{j, d, n}+Y_{j, d+1, n}+Y_{j, d+2, n}\right) \leq 2 \\
& \forall j, d, n \\
& \left(Z_{k, d, n}+Z_{k, d+1, n}+Z_{k, d+2, n}\right) \leq 2 \\
& \forall k, d, n \\
& \left(X_{i, d, e}+X_{i, d, n}\right) \leq 1 \\
& \forall i, d, e, n \\
& \left(Y_{j, d, e}+Y_{j d n}\right) \leq 1 \\
& \forall j, d, e, n \\
& \left(Z_{k, d, e}+Z_{k, d, n}\right) \leq 1 \\
& 8 \leq \sum_{i} X_{i, d, m}+\sum_{j} Y_{j, d, m}+\sum_{k} Z_{k, d, m} \leq 10 \\
& \forall k, d, e, n \\
& \forall d, m \\
& 7 \leq \sum_{i} X_{i, d, e}+\sum_{j} Y_{j, d, e}+\sum_{k} Z_{k, d, e} \leq 9 \\
& 7 \leq \sum_{i} X_{i, d, n}+\sum_{j} Y_{j, d, n}+\sum_{k} Z_{k, d, n} \leq 9 \\
& \sum_{j} Y_{j, d, m}+\sum_{k} Z_{k, d, m} \geq 2 \\
& \sum_{j} Y_{j, d, e}+\sum_{k} Z_{k, d, e} \geq 2 \\
& \sum_{j} Y_{j, d, n}+\sum_{k} Z_{k, d, n} \geq 2 \\
& 176 \leq \sum_{d}\left(6 X_{i, d, m}+6 X_{i, d, e}+19 X_{i, d, n}\right) \leq 352 \\
& \forall i, m, e, n \\
& 176 \leq \sum_{d}\left(6 Y_{j, d, m}+6 Y_{j, d, e}+19 Y_{j, d, n}\right) \leq 352 \\
& \forall j, m, e, n \\
& 176 \leq \sum_{d}\left(6 Z_{k, d, m}+6 Z_{k, d, e}+19 Z_{k, d, n}\right) \leq 352 \\
& \forall k, m, e, n \\
& \sum_{k}\left(Z_{k, d, l}\right) \leq C_{d, l}
\end{aligned}
$$




$$
\begin{aligned}
& S_{i, d, l} \geq \mu \times X_{i, d, l} \\
& O_{j, d, l} \geq \mu \times Y_{j, d, l} \\
& T_{i, d, l} \geq \mu \times Z_{k, d, l} \\
& X_{i d l} \in\{0,1\}, Y_{j d l} \in\{0,1\}, Z_{k d l} \in\{0,1\}
\end{aligned}
$$$$
\forall i, d, l
$$$$
\forall j, d, l
$$$$
\forall i, d, l
$$

Constraint (3.3) shows that a male nurse cannot work the morning shift after the night shift. Constraint (3.4) indicates that a female nurse cannot work the morning shift without a child after working the night shift. Constraint (3.5) displays that a female nurse with a child cannot work the morning shift after the night shift. Constraint (3.6) assures that a male nurse is not arranged to work three consecutive night shifts during the same working period. Constraint (3.7) assures that a female nurse is not arranged to work three consecutive night shifts during the same working period without a child. Constraint (3.8) assures that a female nurse with a child is not arranged to work three consecutive night shifts during the same working period. Constraint (3.9) indicates that a male nurse is not arranged to work two consecutive evening and night shifts in the same working day during the same working period. Constraint (3.10) assures that a female nurse is not arranged to work two consecutive evening and night shifts in the same working day during the same period without a child. Constraint (3.11) shows that a female nurse with a child is not arranged to work two consecutive evening and night shifts in the same working day during the same period. Constraint (3.12) illustrates the minimum and the maximum number of nurses needed in each morning shift. Constraint (3.13) shows the minimum and the maximum number of nurses needed in each evening shift. Constraint (3.14) represents the minimum and the maximum number of nurses needed each night shift. Constraint (3.15) shows the minimum number of female nurses (with and without children) on the morning shift. Constraint (3.16) displays the minimum number of female nurses (with and without children) on the evening shift. Constraint (3.17) shows the minimum number of female nurses (with and without children) on the night shift. Constraint (3.18) indicates the minimum and maximum hours allowed for a male nurse to work. Constraint (3.19) shows a female nurse's minimum and maximum hours to work without a child. Constraint (3.20) shows a female nurse's minimum and maximum hours to work with a child. Constraint (3.21) shows the maximum number of nurses, with a child, in each shift based on the kindergarten's capacity (for the emergency department). Constraint (3.22) assures the minimum confidence interval of each male nurse's assignment to shifts is through $\mu$. Constraint (3.23) assures the minimum confidence interval of each female nurse's assignment, without a child, to shifts is through $\mu$. Constraint (3.24) assures the minimum confidence interval of each female nurse's assignment, with a child, to shifts is through $\mu$. Constraint (3.25) states the type of decision variables of the current model. In addition, you can see the conceptual model in Figure 1 .

\section{Methodology solutions}

This study used a two-stage approach for nurse scheduling in the Emergency Unit of Kamkar Hospital of Qom, Iran. First, experts' opinions and previous studies on nurses' performance collected nurse rating criteria. The nurses were then ranked based on their monthly performance using the fuzzy TOPSIS method.

In this stage, the nurses' certainty of the assigned shifts is measured using the Z-number method. Z-number were used in this study to obtain the nurses' preferences and the reliability of their $Z$ values. In fact, in addition to a better expression of his/her opinion, each nurse can express his/her certainty of opinion. Finally, certainty can be regarded as an essential input of the model. In conclusion, the results' reliability was improved by considering it as an input, making it more applicable in real environments. This method is explained further below.

\subsection{Z-number method}

Zadeh [52] introduced Z-number to calculate uncertain data. Z-number is the ternary fuzzy level and entails general data limitation principles, which refers to the range of values a variable can take. A Z-number has two components of $Z=(A, B)$. The first component $(A)$ represents the fuzziness of a variable and the second 


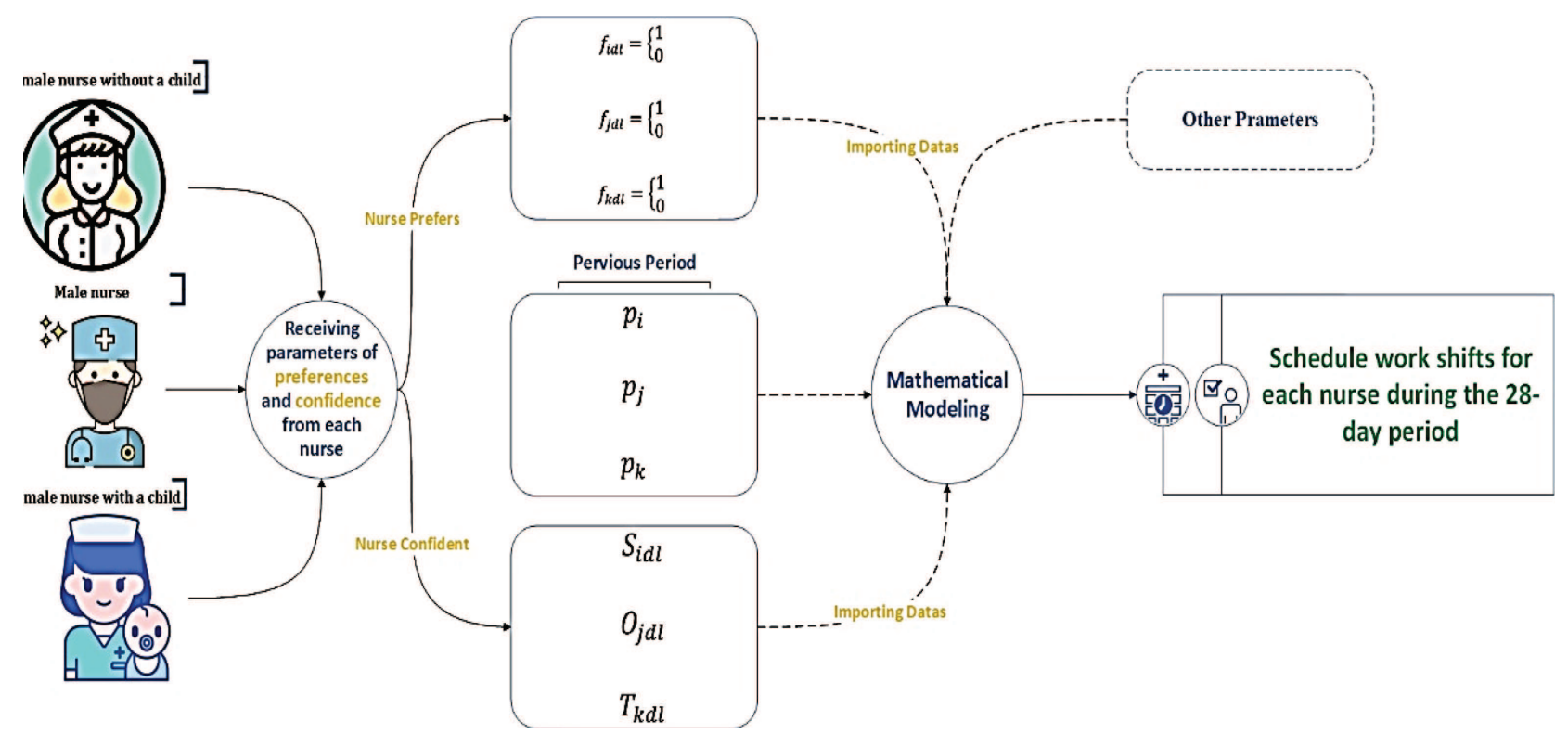

Figure 1. A conceptual model.

component $(B)$ represents the restriction on the reliability of $A$. A Z-number is introduced with three components $(X, A, B)$, in which $X$ is an uncertain value, a refers to the value of $X$, and $B$ refers to the degree of certainty in $X=A$. In classical fuzzy numbers, counters only include Set $A$, and it is believed that $Z$ belongs to Set $A$, whereas, in a Z-number, $Z$ belongs to set $A$ with a degree of certainty, represented by $B$. The degree of uncertainty refers to trust, certainty, degree of trust, probability, feasibility, etc. Therefore, reliability in a Znumber can be represented in the definite, probable, or feasible form. A Z-number is more capable than a fuzzy theory representing human knowledge and dealing with functional uncertainty [1,51]. Soroudi and Amraee [46] investigated different uncertainty modeling approaches and showed that a Z-number is more capable than other methods. For the first time [7] combined Z-number results with DEA. In their model, the inputs and outputs of DEA are obtained from experts in the form of Z-number. This way, they could reduce uncertainty, one of the most critical issues in many real problems.

\subsubsection{Conversion of Z-number into Fuzzy numbers}

Assume that $(\tilde{Z}=\tilde{A}+\tilde{B})$ is a fuzzy number:

$$
\tilde{B}=\left\{x, \mu_{\tilde{B}}(x) \mid x \in[0,1]\right\} .
$$

Based on $\tilde{B}$. It is a triangular fuzzy number. It can be written as equation (4.2).

$$
\tilde{B}_{\pi_{n}\left(R_{n}\right)}=\operatorname{TFN}(\alpha, \beta, \gamma) \text {. }
$$

Next, the fuzzy number $\tilde{B}$. According to equation (33) of $\mathrm{Hu}$ and Liao [23] is converted into an absolute number.

$$
\text { if } \tilde{B}=\operatorname{TFN}(\alpha, \beta, \gamma) \Rightarrow B=\frac{\alpha+\beta+\gamma}{3} .
$$

Equation (4.4) converts Z-number into a fuzzy number [27].

$$
\text { if } \tilde{A}_{\pi_{n}\left(R_{n}\right)}=\operatorname{TFN}(\dot{\alpha}, \dot{\beta}, \dot{\gamma})
$$


TABLE 1. Expressive constraints on the possibility of attending work shifts.

\begin{tabular}{ll}
\hline \hline Fuzzy number & Expressive variable \\
\hline$(0.25,0.00,0.00)$ & Infeasibility \\
$(0.50,0.25,0.00)$ & Very low \\
$(0.75,0.50,0.25)$ & Low \\
$(1,0.75,0.75)$ & High \\
$(1,1,0.75)$ & Very high \\
\hline
\end{tabular}

TABLE 2. Expressive constraints on certainty about selecting shifts.

\begin{tabular}{ll}
\hline \hline Fuzzy number & Expressive variable \\
\hline$(0.7,0.6,0.5)$ & Likely \\
$(0.85,0.75,0.65)$ & Usually \\
$(1,1,0.8)$ & Sure \\
\hline & \\
& \\
& $\operatorname{TFN}(\sqrt{B} \alpha, \sqrt{B} \beta, \sqrt{B} \delta)$.
\end{tabular}

Finally, each fuzzy number is converted into an absolute number using equation (4.5) [23].

$$
\text { if } \tilde{Z}=\operatorname{TFN}(\sqrt{B} \alpha, \sqrt{B} \beta, \sqrt{B} \delta) \Rightarrow \mathrm{Z}=\frac{\sqrt{B} \alpha+\sqrt{B} \beta+\sqrt{B} \delta}{3} \text {. }
$$

The expressive constraints on the feasibility of existing relationships based on Chang et al. [12] can be seen in Table 1. The expressive constraints and cross-fuzzy numbers have been used [7] (see Tab. 2).

Accordingly, through interviews with each of the nurses, we got their confidence level for working shifts through the Z-number method.

\subsubsection{Nurse rating criteria}

Obtaining appropriate criteria for ranking nurses was done through interviewing experts' opinions and relevant literature. For example, Meghdad et al. [33] extracted the indices of performance evaluation based on the 360degree model, including head nurses, colleagues, nurses, patients, and their companions, in a study conducted in a hospital affiliated with the University of Medical Sciences of Kashan. The selected criteria and sub-criteria were:

(1) Personality characteristics: honesty, interest, sense of compassion, control emotions, and prioritizing organizational interests to self-interests.

(2) Human skills: good relationship with patients, educating patients, protecting patients' privacy, treating colleagues respectfully, and cooperating with colleagues.

(3) Conceptual skills: decision-making in uncertain space, adaption with changes, identification of weaknesses and strengths, creativity, and innovation.

(4) Rules and Regulations: introducing patient to auxiliary nurse, wearing uniform properly, paying attention to patient safety, and checking up the patient regularly.

(5) Technical skills: working with medical equipment, taking medical measures properly, and documenting patient's history.

Among five sets of evaluation criteria, "human skills" obtained the highest score, and among the sub-criteria, "good relationship with the patient" and "cooperation with colleagues" obtained the highest scores. Because 
TABLE 3. Values of preferences in pairwise comparison.

\begin{tabular}{ll}
\hline \hline Preferences & Numerical value \\
\hline Completely preferred, completely more important, or completely higher utility & 9 \\
Very high preference, importance, or utility & 7 \\
High preference, importance, or utility & 5 \\
Low preference, importance, or utility & 3 \\
Equal preference, importance, or utility & 1 \\
Preference between these values & $2,4,6,8$ \\
\hline
\end{tabular}

TABLE 4. Range of priorities, fuzzy TOPSIS.

\begin{tabular}{lllll}
\hline \hline \multirow{2}{*}{ Row } & \multirow{2}{*}{ Priorities } & \multicolumn{3}{c}{ The fuzzy equivalent of priorities } \\
\cline { 3 - 5 } & & Low threshold (L) & Moderate threshold (M) & High threshold (U) \\
\hline 1 & Very weak & 1 & 1 & 3 \\
2 & Poor & 1 & 3 & 5 \\
3 & Moderate & 3 & 5 & 7 \\
4 & Good & 5 & 7 & 9 \\
5 & Very good & 7 & 9 & 11 \\
\hline
\end{tabular}

performance appraisal criteria can be different from organization to organization. Therefore, we considered conditions of the emergency department and, using questionnaires and interviews with the nursing unit, removed some of the criteria presented in the research of Meghdad et al. [33] and integrated some of them. Thus, the final list of criteria was determined as follows:

- Being honest.

- Having interest, compassion, and patience.

- Treating patients properly.

- Treating patients respectfully and cooperating with colleagues.

- Checking patients regularly.

- Having a neat and clean appearance (uniform, compliance with regulations, etc).

- Having skill in working with medical equipment and taking proper medical measures.

- Documenting patient's history.

\subsubsection{Giving weight using AHP}

Saaty [41] developed the hierarchical analysis method. This technique is a powerful and flexible multi-criteria decision-making method that can solve complex problems at different levels. The hierarchical analysis is a decision-making method that highlights the importance of intuitive judgments of a decision-maker and stability of comparison of alternative options in the decision-making process. Table 3 was used to create a pairwise comparison matrix.

\subsection{Rating nurses using fuzzy TOPSIS}

Fuzzy TOPSIS, developed by Hwang and Yoon [25], is a well-known and highly applicable multi-criteria decision-making method used to rate items in a fuzzy environment. To complete the fuzzy decision matrix, a five-point Likert scale (see Tab. 4), anchored from "very weak" to "very good," can be used. 


\subsection{Epsilon-constraint}

Optimization refers to finding one or more feasible solutions that comply with the ultimate values of one or more objectives. A standard method to obtain an effective boundary is the epsilon-constraint method. In this method, an objective function is considered the primary objective function, and other objective functions are limited at an acceptable threshold value. The value may change to produce Pareto solutions. The decision-maker makes this change to generate Pareto solutions.

An epsilon-constraint method is a well-known approach for dealing with multi-objective problems, which solves such problems by transforming all objective functions, except one, to the constraints at each stage [16]. The Pareto front can be made using the epsilon-constraint method.

$$
\begin{array}{ll}
\min & f_{1}(x) \\
x \in X & \\
& f_{2}(x) \leq \varepsilon_{2} \\
& \cdots \\
& f_{n}(x) \leq \varepsilon_{n} .
\end{array}
$$

\section{Stage of epsilon-constraint method}

(1) Selecting one of the objective functions as the primary objective function of the problem.

(2) Solving the problem based on the selected objective functions and obtaining the optimal values of each objective function.

(3) Dividing the range between two optimal values of secondary objective functions into a specific number and forming the return table for (determining the optimal values of the objective functions for a different solution).

(4) Solving the problem using the primary objective function with each value.

(5) Reporting obtained Pareto solutions.

In the epsilon-constraint method, the first objective function is the primary objective function, and the second is the secondary objective function. Then, two failures were considered for each objective. In total, a maximum of 4 Pareto points was generated for each problem. The best optimal solution for the objective function can be found among the Pareto points of the epsilon-constraint method.

\section{Case Study: Emergency unit of Kamkar Hospital of Qom}

This section addressed a two-stage approach to nurse scheduling in the Emergency Unit of Kamkar Hospital of Qom, Iran. In the first stage, the head nurse's recorded information and opinions in the previous period were used to rate nurses based on their performance evaluation using a hierarchal analysis method. Moreover, nurses' shift preferences were evaluated based on the nurses' score in Questionnaire 1 in Appendix $(0=$ dissatisfied with the shift and 1 = satisfied with the shift). In addition to each nurse's satisfaction with the shift, the degree of his/her certainty was measured using the questionnaire's expressive constraints (Tabs. 1 and 2). These were used as the model's input in the second stage.

Kamkar-Arabnia Hospital is one of the old hospitals in region 7 of Qom Province. Since the hospital is located in the central area of Qom and near the Fatima Masumeh Shrine, it has especially important. This hospital's emergency unit comprises 36 nurses (18 male nurses, 11 female nurses without a child, and seven female nurses with a child) providing around-the-clock nursing services. The one-month shift schedule had been manually generated before applying the model. This conventional scheduling method was accompanied by many problems for this unit, particularly for the head nurse. Some of the most significant challenges are:

- The majority of nurses complained about the arranged shifts.

- We are creating a sense of discrimination among nurses concerning scheduled shifts. 


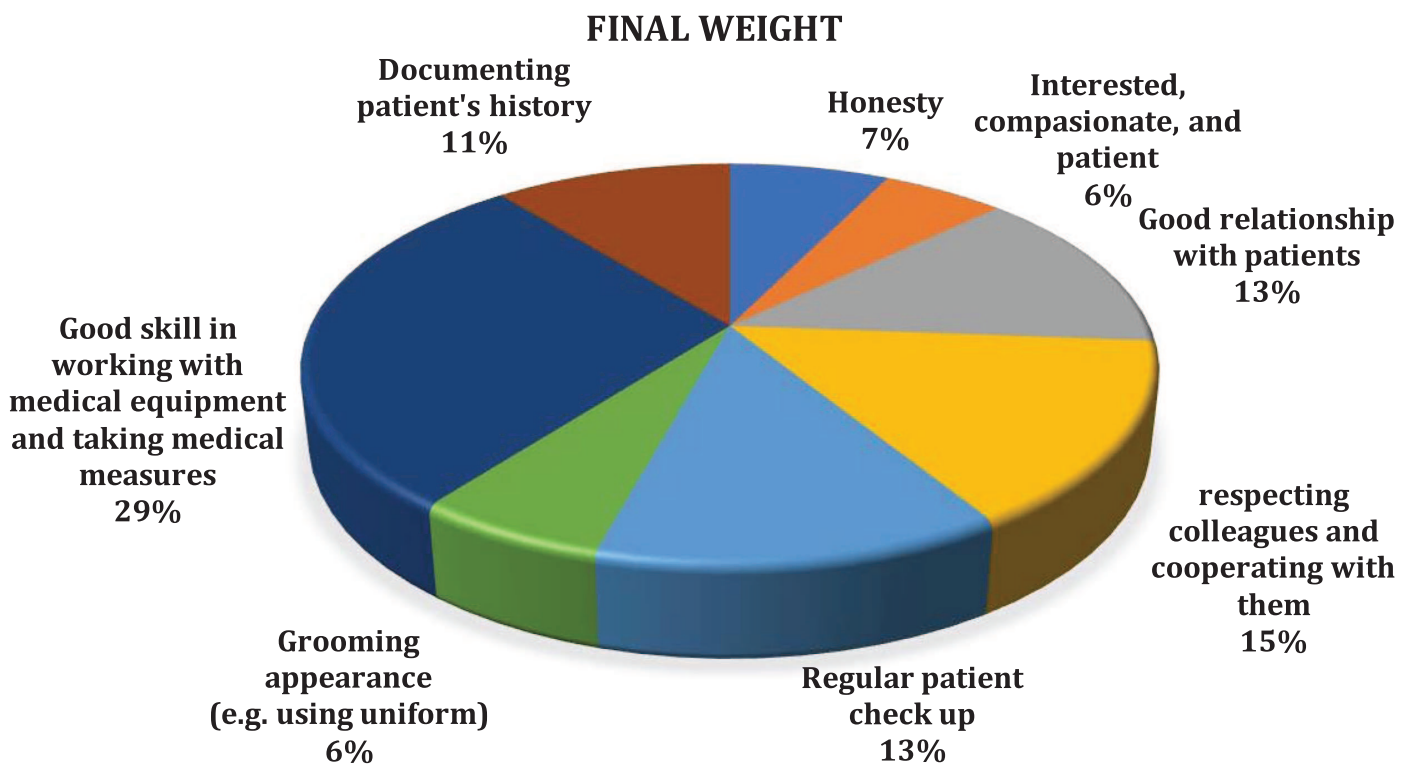

Figure 2. The final weight of criteria.

- Chaos during the planning period due to emergency absences.

- Nurses' dissatisfaction subsequently reduced patients' and others' satisfaction and reduced the whole system's productivity.

- The time-consuming process of manual nurse scheduling is typically done during the last few days of each month.

- The reluctance of nurses towards higher performance due to discrimination.

The researcher extracted nurse performance evaluation criteria and sub-criteria through interviewing experts (doctors, nurses, and head nurses) and reviewing the literature to improve the conditions. Further, AHP and expert interviews (second questionnaire) were used to obtain the criteria' weight (see Fig. 2).

At the end of each period and after completing each nurse's information, the nurses were rated based on their performance in the previous period using the fuzzy TOPSIS. Moreover, each nurse's preferences and certainty regarding their arranged shifts were collected using Questionnaire 1. As was explained, each nurse's collected opinions concerning scheduled shifts are based on the Z-number method, consisting of both a feasible shift and certainty. Finally, the opinions were converted into final numbers and inputted into the model using the fuzzy TOPSIS and Tables 1 and 2.

\subsection{The results of the proposed model}

Given the problem's dimensions, the mathematical model generated an optimal result in less than one minute (CPU: Core i7, 2.4 GHz; Ram: $8 \mathrm{~GB}$ ). The epsilon-constraint method was used to solve the model. Figure 3 shows the results from objective functions for various iterations.

Moreover, the results from solving the model and shift assignments in the first, second, third, and fourth weeks are presented in Table 5.

\subsection{Sensitivity analysis}

To validate the parameters of the model and their impacts on the objective functions, some sensitivities are carried out. 


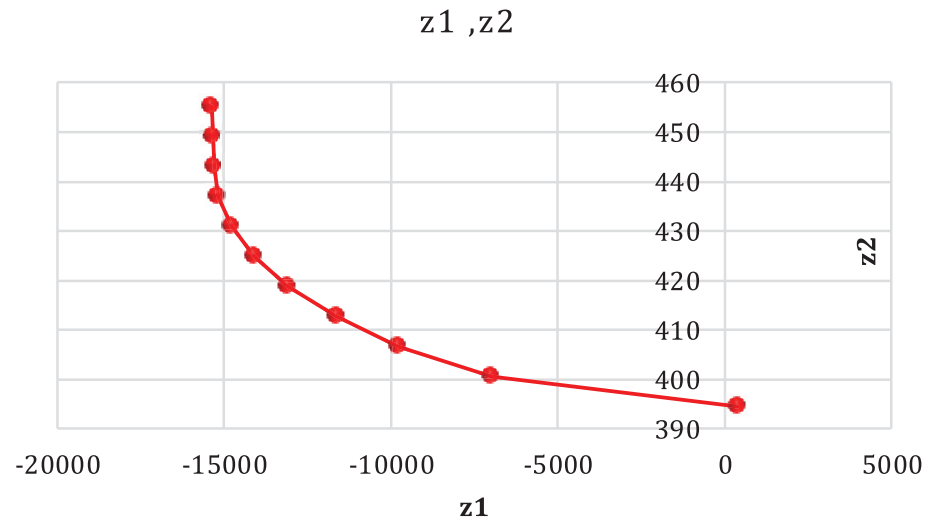

Figure 3. Values of the objective function for various iterations.

\subsubsection{Sensitivity analysis on $\pi_{1}$ and $\pi_{2}$}

In the first objective function, $\pi_{1}$ and $\pi_{2}$ show the importance of considering desired and undesired preferences, respectively. The values of the objective function for $\pi_{1}=\pi_{2}$ and $2 \pi_{1}=\pi_{2}$ are presented in Figures 4 and 5 , respectively.

According to the pattern of changes in the objective function, the first objective function's value reduces some iterations and increases some other iterations by increasing the coefficient of undesired preferences. These changes largely depend on curses' competition to avoid a specific shift.

\subsubsection{Sensitivity analysis of confidence level $(\mu)$}

In this sub-section, with increasing the coefficient of $\mu$ in the constraints, the model is optimized to avoid scheduling at a confidence level lower than $\mu$. The values of the objective function after solving the problem with $\mu=0.2$ and $\mu=0.6$ are, respectively, presented in Figures 5 and 6 .

According to the trend of changes of $\mu$, the values of the first and second objective functions increase with increasing this parameter; however, the effect of this increase on the second objective function is significant because of the increased confidence level of the model. Given that nurses reported a higher confidence level when satisfied with their shift, a slight increase in the first objective function is justified. Moreover, the model becomes infeasible at values higher than $\mu=0.65$.

\section{Managerial insights}

Based on studies in scheduling nurses' work shifts, most articles have proposed a mathematical model to optimize nurses' work shifts. The general attitude in these studies has been to observe hospitals and medical centers' rules and policies. Most of them have not considered nurses' preferences, or if they deal with this issue, they have sought to create conditions for creating equality between nurses. In general, the following items have been included as indicators of creating equality between nurses in research:

- An equal number of night shifts.

- The number of weekends is equal.

- The total number of shifts is equal.

- Observe the preferences of nurses equally for all of them.

Previous studies have shown that increasing nurses' satisfaction depends on applying their preferences regarding favorable and unfavorable work shifts during the planning period. However, in studies conducted in this field, such as the research of and face-to-face interviews with the nurses of the mentioned hospital, it was found 
TABLE 5. Results from assigning nurses to various shifts.

\begin{tabular}{|c|c|c|c|c|c|c|c|}
\hline \multirow{2}{*}{$\begin{array}{l}\text { Personnel } \\
\text { number }\end{array}$} & \multicolumn{7}{|c|}{ First week } \\
\hline & 1 & 2 & 3 & 4 & 5 & 6 & 7 \\
\hline 1 & M & & & $M \& N$ & $\mathrm{E}$ & & \\
\hline 2 & & & M & $\mathrm{M} \& \mathrm{E}$ & $\mathrm{N}$ & $\mathrm{E}$ & $M \& E$ \\
\hline 3 & & $\mathrm{M} \& \mathrm{E}$ & & $\mathrm{E}$ & $\mathrm{M}$ & $\mathrm{N}$ & $\mathrm{E}$ \\
\hline 4 & $\mathrm{E}$ & $\mathrm{N}$ & & $\mathrm{M} \& \mathrm{E}$ & M & M & M \\
\hline 5 & & M & $\mathrm{N}$ & & & $\mathrm{N}$ & $\mathrm{E}$ \\
\hline 6 & M & $\mathrm{E}$ & M & & & M & \\
\hline 7 & M & $\mathrm{E}$ & & $\mathrm{N}$ & $\mathrm{N}$ & & $\mathrm{M}$ \\
\hline 8 & $\mathrm{M} \& \mathrm{E}$ & $M \& N$ & & & $\mathrm{E}$ & & $\mathrm{E}$ \\
\hline 9 & $\mathrm{E}$ & & $\mathrm{N}$ & & $\mathrm{E}$ & $\mathrm{E}$ & $\mathrm{N}$ \\
\hline 10 & $\mathrm{~N}$ & & $\mathrm{~N}$ & & & $\mathrm{E}$ & \\
\hline 11 & M & & & & & $\mathrm{M}$ & M \\
\hline 12 & & & $\mathrm{E}$ & $\mathrm{N}$ & & & $\mathrm{E}$ \\
\hline 13 & & M & & & & M & \\
\hline 14 & $\mathrm{M}$ & $\mathrm{M} \& \mathrm{~N}$ & & & $\mathrm{E}$ & $\mathrm{E}$ & \\
\hline 15 & $\mathrm{E}$ & & & M & & $\mathrm{E}$ & \\
\hline 16 & & & & & $\mathrm{~N}$ & & \\
\hline 17 & $\mathrm{E}$ & & $\mathrm{N}$ & $\mathrm{N}$ & & & \\
\hline 18 & & & & $\mathrm{M}$ & & $M \& N$ & \\
\hline 19 & & $\mathrm{E}$ & M & & $M \& N$ & M & M \\
\hline 20 & $\mathrm{E}$ & $\mathrm{N}$ & $\mathrm{E}$ & & $\mathrm{N}$ & $\mathrm{N}$ & $\mathrm{E}$ \\
\hline 21 & & & $\mathrm{E}$ & $\mathrm{E}$ & M & & \\
\hline 22 & & & $\mathrm{~N}$ & & $M \& N$ & & \\
\hline 23 & $\mathrm{~N}$ & & $\mathrm{E}$ & & M & $\mathrm{N}$ & \\
\hline 24 & $\mathrm{~N}$ & $\mathrm{~N}$ & $\mathrm{E}$ & & $\mathrm{E}$ & & M \\
\hline 25 & & $\mathrm{M} \& \mathrm{E}$ & $\mathrm{N}$ & & & & $\mathrm{N}$ \\
\hline 26 & $\mathrm{~N}$ & & & $\mathrm{E}$ & $\mathrm{E}$ & & \\
\hline 27 & & $\mathrm{~N}$ & $\mathrm{E}$ & $M \& N$ & & & $\mathrm{~N}$ \\
\hline 28 & & M & & M & & $\mathrm{N}$ & \\
\hline 29 & & $\mathrm{E}$ & M & $\mathrm{N}$ & & & $\mathrm{N}$ \\
\hline 30 & & $\mathrm{E}$ & & M & $M \& E$ & M & M \\
\hline 31 & $\mathrm{~N}$ & & & $\mathrm{E}$ & & $M \& N$ & \\
\hline 32 & & $\mathrm{~N}$ & $\mathrm{~N}$ & & M & & $\mathrm{N}$ \\
\hline 33 & $\mathrm{M}$ & & $\mathrm{M}$ & & & & \\
\hline 34 & $\mathrm{~N}$ & & & $\mathrm{~N}$ & & $\mathrm{M} \& \mathrm{E}$ & $M \& E$ \\
\hline 35 & & M & M & & $\mathrm{N}$ & & $\mathrm{N}$ \\
\hline 36 & $M \& N$ & $\mathrm{E}$ & M & $\mathrm{E}$ & & & $\mathrm{N}$ \\
\hline
\end{tabular}

that the equality of nurses' preferences does not necessarily increase their satisfaction. The concepts of justice and equality of work are different from each other. One way to apply justice in nurses' work shifts is to prioritize nurses' preferences based on their performance. Thus, in this research, according to previous research as well as interviews with experts, we proceeded to extract appropriate criteria for ranking nurses. Then, using the hierarchical analysis technique and expert opinions, the weight of the criteria was determined. Using the fuzzy TOPSIS technique, each nurse's rank was determined at the end of the course.

In this step, we received information about nurses' presence in work shifts using the Z-number method to prevent accidental absences. Selected shifts can be more reliable. 
TABLE 5. continued.

\begin{tabular}{|c|c|c|c|c|c|c|c|}
\hline \multirow{2}{*}{$\begin{array}{l}\text { Nurse } \\
\text { number }\end{array}$} & \multicolumn{7}{|c|}{ Second week } \\
\hline & 1 & 2 & 3 & 4 & 5 & 6 & 7 \\
\hline 1 & & & & $\mathrm{E}$ & M & $\mathrm{E}$ & $\mathrm{E}$ \\
\hline 2 & & M & & $\mathrm{E}$ & & M & M \\
\hline 3 & & $\mathrm{~N}$ & $\mathrm{~N}$ & & M\&N & & M \\
\hline 4 & & M\&E & & M & M & $\mathrm{N}$ & \\
\hline 5 & M & & $\mathrm{N}$ & & $\mathrm{N}$ & & \\
\hline 6 & M & $\mathrm{N}$ & $\mathrm{E}$ & $\mathrm{M} \& \mathrm{~N}$ & & $\mathrm{E}$ & $\mathrm{E}$ \\
\hline 7 & $\mathrm{M} \& \mathrm{~N}$ & & & $M \& E$ & & $\mathrm{E}$ & \\
\hline 8 & $\mathrm{E}$ & $\mathrm{M}$ & & & $\mathrm{M}$ & & \\
\hline 9 & $\mathrm{~N}$ & & $M \& E$ & & & & M \\
\hline 10 & & & $M \& E$ & & $\mathrm{~N}$ & $\mathrm{E}$ & $\mathrm{E}$ \\
\hline 11 & M & M & $\mathrm{N}$ & $\mathrm{N}$ & & & \\
\hline 12 & M & M & & $\mathrm{N}$ & & $\mathrm{N}$ & $\mathrm{E}$ \\
\hline 13 & $\mathrm{E}$ & & $M \& N$ & & M & & M \\
\hline 14 & & $\mathrm{~N}$ & & $\mathrm{~N}$ & & $\mathrm{~N}$ & \\
\hline 15 & & $\mathrm{~N}$ & & $M \& E$ & & & M \\
\hline 16 & & $\mathrm{~N}$ & $\mathrm{E}$ & & $\mathrm{N}$ & & $\mathrm{N}$ \\
\hline 17 & $\mathrm{E}$ & & $\mathrm{N}$ & & $\mathrm{E}$ & & $M \& N$ \\
\hline 18 & $M \& N$ & & & & & $M \& N$ & $\mathrm{~N}$ \\
\hline 19 & $\mathrm{~N}$ & $\mathrm{E}$ & & & M & $\mathrm{E}$ & \\
\hline 20 & $\mathrm{~N}$ & & $\mathrm{E}$ & & M & & \\
\hline 21 & & M\&E & & $M \& N$ & $\mathrm{~N}$ & & \\
\hline 22 & $\mathrm{~N}$ & & $M \& N$ & $\mathrm{E}$ & & & \\
\hline 23 & & & & M & & $M \& E$ & \\
\hline 24 & $M \& E$ & & M & M & $\mathrm{E}$ & $\mathrm{N}$ & \\
\hline 25 & & $\mathrm{E}$ & & $\mathrm{E}$ & M & $\mathrm{M}$ & \\
\hline 26 & & $\mathrm{E}$ & & $\mathrm{N}$ & & $\mathrm{N}$ & \\
\hline 27 & $\mathrm{E}$ & M\&E & $\mathrm{N}$ & & & M & $\mathrm{N}$ \\
\hline 28 & M & & M & $\mathrm{N}$ & & M & \\
\hline 29 & $\mathrm{E}$ & & $\mathrm{E}$ & & $\mathrm{N}$ & & $M \& E$ \\
\hline 30 & & M & $\mathrm{E}$ & & $\mathrm{E}$ & & $\mathrm{E}$ \\
\hline 31 & & & & M & $\mathrm{E}$ & $\mathrm{E}$ & \\
\hline 32 & $\mathrm{~N}$ & & M & $\mathrm{N}$ & & & M \\
\hline 33 & & $\mathrm{M} \& \mathrm{~N}$ & & & $\mathrm{E}$ & M & $\mathrm{E}$ \\
\hline 34 & & & M & & $\mathrm{N}$ & & \\
\hline 35 & $\mathrm{E}$ & $\mathrm{N}$ & & & $\mathrm{M} \& \mathrm{E}$ & & $M \& N$ \\
\hline 36 & & & & $\mathrm{E}$ & & M & $\mathrm{N}$ \\
\hline
\end{tabular}

In the second stage, we modelled the problem based on the policies and rules of the hospital. To increase nurses' preferences based on justice and reduce accidental absences during the planning period, we used the Epsilon constraint method and GAMS software to solve the model.

Thus, according to the above, we could take positive steps to solve the emergency department of Kamkar Hospital's emergency department in Qom province. Confidence decreased when nurses chose shifts.

\section{Conclusion}

This study addressed nurse scheduling in the Emergency Unit of Kamkar Hospital, Qom. Among the most important challenges facing this emergency unit before applying the model were:

- Nurses' complaints about injustice concerning scheduled shifts. 
TABLE 5. continued.

\begin{tabular}{|c|c|c|c|c|c|c|c|}
\hline \multirow{2}{*}{$\begin{array}{l}\text { Nurse } \\
\text { number }\end{array}$} & \multicolumn{7}{|c|}{ Third week } \\
\hline & 1 & 2 & 3 & 4 & 5 & 6 & 7 \\
\hline 1 & $\mathrm{M} \& \mathrm{~N}$ & & & & & $\mathrm{~N}$ & \\
\hline 2 & & & $\mathrm{~N}$ & $\mathrm{E}$ & $\mathrm{E}$ & & $M \& E$ \\
\hline 3 & & $\mathrm{~N}$ & & & $\mathrm{E}$ & & \\
\hline 4 & $\mathrm{~N}$ & $\mathrm{~N}$ & $\mathrm{E}$ & M & M\&E & M & $M \& N$ \\
\hline 5 & $\mathrm{~N}$ & $\mathrm{~N}$ & $\mathrm{E}$ & & & & \\
\hline 6 & M & $\mathrm{N}$ & $\mathrm{N}$ & $\mathrm{E}$ & $\mathrm{N}$ & & $\mathrm{E}$ \\
\hline 7 & & $\mathrm{E}$ & & $\mathrm{N}$ & & $\mathrm{E}$ & $\mathrm{E}$ \\
\hline 8 & $\mathrm{~N}$ & & & $\mathrm{E}$ & M & & \\
\hline 9 & $\mathrm{M} \& \mathrm{E}$ & & & $M \& N$ & & & \\
\hline 10 & & M\&E & M & & $\mathrm{N}$ & $\mathrm{N}$ & \\
\hline 11 & & M\&E & $M \& N$ & & & $\mathrm{M} \& \mathrm{E}$ & M \\
\hline 12 & M & M & $\mathrm{N}$ & & & $M \& E$ & $\mathrm{E}$ \\
\hline 13 & $\mathrm{E}$ & & & M & M & M & $\mathrm{N}$ \\
\hline 14 & & M & & $\mathrm{N}$ & & & \\
\hline 15 & $\mathrm{E}$ & & M & M & $\mathrm{N}$ & & \\
\hline 16 & & & & $\mathrm{~N}$ & & & $\mathrm{~N}$ \\
\hline 17 & & & & $M \& E$ & & & $M \& N$ \\
\hline 18 & & & $M \& E$ & & $\mathrm{~N}$ & $\mathrm{~N}$ & \\
\hline 19 & M & M & $\mathrm{N}$ & & & $\mathrm{N}$ & \\
\hline 20 & & & & & $\mathrm{M} \& \mathrm{~N}$ & $\mathrm{E}$ & $\mathrm{N}$ \\
\hline 21 & & M & M & $\mathrm{E}$ & M & & \\
\hline 22 & M & $\mathrm{E}$ & $\mathrm{E}$ & & & $\mathrm{N}$ & \\
\hline 23 & M & & & $\mathrm{M} \& \mathrm{~N}$ & & $\mathrm{~N}$ & $\mathrm{~N}$ \\
\hline 24 & M & & $M \& E$ & M & $\mathrm{E}$ & & \\
\hline 25 & $\mathrm{~N}$ & & $\mathrm{~N}$ & & & & $\mathrm{E}$ \\
\hline 26 & & $\mathrm{E}$ & & & $\mathrm{N}$ & & $M \& E$ \\
\hline 27 & $\mathrm{E}$ & & & & & & \\
\hline 28 & & & M & & M\&E & $\mathrm{E}$ & \\
\hline 29 & $\mathrm{E}$ & $\mathrm{M} \& \mathrm{~N}$ & & & & M & \\
\hline 30 & $\mathrm{E}$ & $\mathrm{N}$ & & & & $M \& E$ & \\
\hline 31 & & $\mathrm{~N}$ & & $\mathrm{~N}$ & & $\mathrm{E}$ & \\
\hline 32 & $\mathrm{E}$ & $\mathrm{E}$ & $M \& E$ & & & & \\
\hline 33 & $\mathrm{~N}$ & & $\mathrm{~N}$ & $\mathrm{E}$ & M\&E & M & $M \& E$ \\
\hline 34 & & M & $\mathrm{E}$ & $\mathrm{N}$ & $\mathrm{N}$ & & $\mathrm{M}$ \\
\hline 35 & & $\mathrm{E}$ & & $\mathrm{M} \& \mathrm{E}$ & $\mathrm{E}$ & $M \& N$ & \\
\hline 36 & $\mathrm{~N}$ & & & & M & & \\
\hline
\end{tabular}

- Nurses' dissatisfaction to enhance their performance quality.

- The nurse scheduling system's lack of clarity results in discrimination among them.

- The time-consuming process of nurse scheduling and related problems for the head nurse.

- Problems associated with frequent nurse absenteeism because of emergency issues during the period.

- Reduced productivity of the nursing system and subsequent productivity of the whole system.

To improve the issues mentioned above, nurses were rated based on their performance evaluation. The desired criteria for performance evaluation were obtained using the questionnaire and literature and its comparison with the existing system.

The criteria were given weight by experts using hierarchical analysis. Moreover, nurses were rated using the fuzzy TOPSIS. In this way, the application of desired and undesired preferences of each nurse depends on their 
TABLE 5. continued.

\begin{tabular}{|c|c|c|c|c|c|c|c|}
\hline \multirow{2}{*}{$\begin{array}{l}\text { Nurse } \\
\text { number }\end{array}$} & \multicolumn{7}{|c|}{ Fourth week } \\
\hline & 1 & 2 & 3 & 4 & 5 & 6 & 7 \\
\hline 1 & & $\mathrm{~N}$ & $\mathrm{E}$ & & $\mathrm{N}$ & $\mathrm{M} \& \mathrm{E}$ & \\
\hline 2 & $\mathrm{~N}$ & & & $\mathrm{E}$ & & M & \\
\hline 3 & M & & & & & $\mathrm{E}$ & $\mathrm{E}$ \\
\hline 4 & & & M & & $\mathrm{M} \& \mathrm{E}$ & & $\mathrm{E}$ \\
\hline 5 & & M\&N & & & $\mathrm{E}$ & & $\mathrm{M}$ \\
\hline 6 & & M & M & & & & \\
\hline 7 & & & $\mathrm{M} \& \mathrm{E}$ & M\&E & $\mathrm{M}$ & & \\
\hline 8 & $\mathrm{~N}$ & & $\mathrm{E}$ & M & $\mathrm{N}$ & & $\mathrm{N}$ \\
\hline 9 & & & $\mathrm{~N}$ & $\mathrm{~N}$ & & & \\
\hline 10 & $\mathrm{M}$ & $\mathrm{N}$ & & & $\mathrm{E}$ & $\mathrm{M}$ & \\
\hline 11 & & M & $\mathrm{E}$ & $\mathrm{E}$ & $\mathrm{E}$ & $\mathrm{E}$ & $\mathrm{M}$ \\
\hline 12 & M & M\&E & & & & M & M \\
\hline 13 & & $\mathrm{E}$ & M & M\&N & & $\mathrm{M} \& \mathrm{E}$ & $\mathrm{N}$ \\
\hline 14 & & & $\mathrm{~N}$ & & & $\mathrm{~N}$ & $\mathrm{~N}$ \\
\hline 15 & $\mathrm{M} \& \mathrm{~N}$ & $\mathrm{E}$ & & M & $\mathrm{N}$ & $\mathrm{N}$ & \\
\hline 16 & $\mathrm{~N}$ & & $\mathrm{~N}$ & & & & $\mathrm{~N}$ \\
\hline 17 & & $\mathrm{E}$ & $\mathrm{N}$ & & $\mathrm{M}$ & & \\
\hline 18 & & $\mathrm{E}$ & & $\mathrm{E}$ & & & M \\
\hline 19 & & M & M & $\mathrm{N}$ & & $\mathrm{N}$ & \\
\hline 20 & & $\mathrm{~N}$ & & $\mathrm{E}$ & $\mathrm{N}$ & & $M \& N$ \\
\hline 21 & $\mathrm{M}$ & M\&E & $\mathrm{N}$ & & $M \& N$ & & M \\
\hline 22 & & & M & $M \& N$ & & & $\mathrm{~N}$ \\
\hline 23 & $\mathrm{E}$ & & $\mathrm{M} \& \mathrm{E}$ & & $\mathrm{M} \& \mathrm{E}$ & & \\
\hline 24 & $\mathrm{~N}$ & & & $\mathrm{E}$ & & $\mathrm{E}$ & \\
\hline 25 & $\mathrm{E}$ & M & & M & $\mathrm{N}$ & $\mathrm{E}$ & $\mathrm{E}$ \\
\hline 26 & & $\mathrm{~N}$ & & M\&E & $\mathrm{N}$ & & $\mathrm{E}$ \\
\hline 27 & $\mathrm{M}$ & M & & & $\mathrm{N}$ & & \\
\hline 28 & M & M\&N & & $\mathrm{N}$ & & $\mathrm{N}$ & $\mathrm{E}$ \\
\hline 29 & & $\mathrm{~N}$ & & & $\mathrm{M} \& \mathrm{E}$ & $\mathrm{E}$ & \\
\hline 30 & $\mathrm{E}$ & & $\mathrm{N}$ & & & & $\mathrm{E}$ \\
\hline 31 & $\mathrm{~N}$ & & & & M & $\mathrm{N}$ & $\mathrm{N}$ \\
\hline 32 & $\mathrm{M} \& \mathrm{E}$ & & $\mathrm{N}$ & & $\mathrm{E}$ & $\mathrm{M} \& \mathrm{~N}$ & \\
\hline 33 & $\mathrm{E}$ & & & & $\mathrm{M}$ & & $M \& N$ \\
\hline 34 & $\mathrm{E}$ & $\mathrm{E}$ & $\mathrm{M} \& \mathrm{E}$ & & & & \\
\hline 35 & & & & M & & M & $\mathrm{E}$ \\
\hline 36 & $\mathrm{~N}$ & & & $\mathrm{~N}$ & & M & $\mathrm{M}$ \\
\hline
\end{tabular}

rate in the previous period. In this way, the desired and undesired preferences application system was clarified, reducing complaints. Also, using Z-number improved the certainty of nurses given the selection of shifts, reducing absenteeism.

Changes in the model's input parameters can lead to better or worse results. This model has two primary objectives; this sector investigated the sensitivity analysis of the model's input parameters and the effects of these changes on these objectives. Also, we analyze the results of the running model on the nursing unit, nurses, patients, and physicians. 


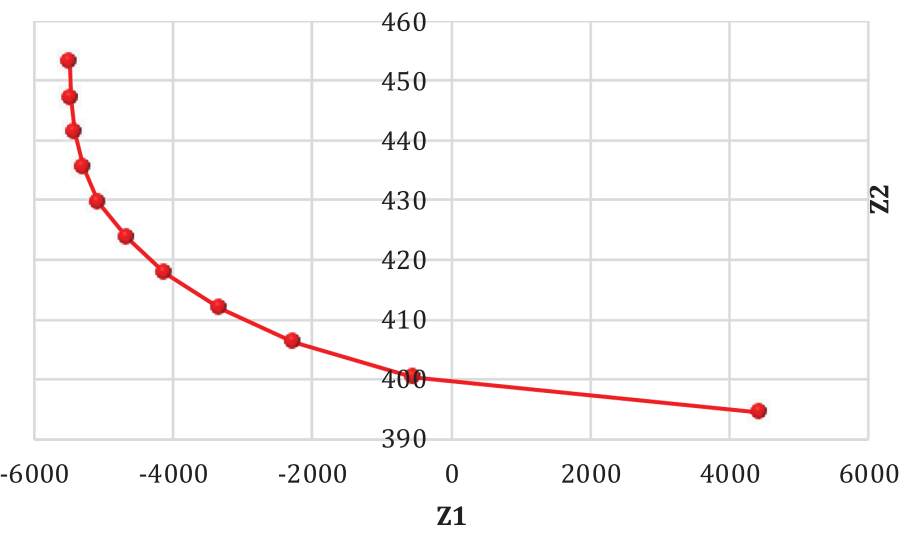

Figure 4 . Value of objective function at $2 \pi 1=\pi 2$.

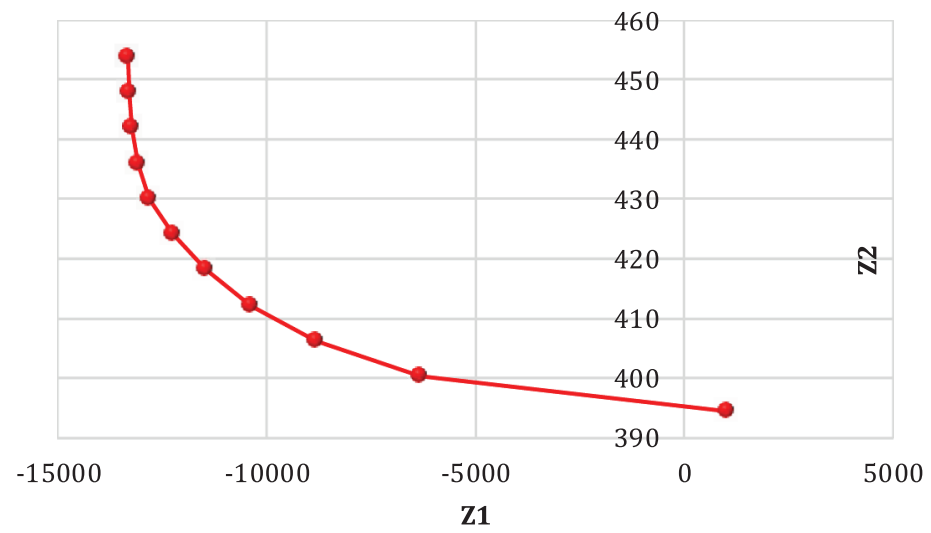

Figure 5. Values of the objective function at $\pi=0.2$.

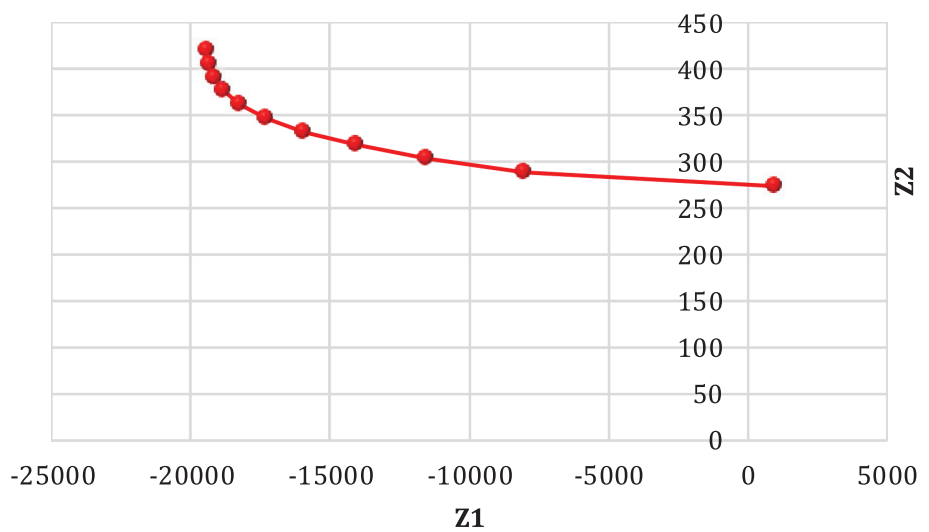

Figure 6 . Values of objective functions at $\pi=0.6$. 


\subsection{Nursing unit}

Before applying the model, nurse scheduling in this unit had been done manually by spending a lot of time and money. The use of this model reduced complaints and scheduling time. According to the nursing unit's report, the number of nurses' absences was reduced by $40 \%$. Also, according to this unit report on the model results, nurses' complaints were reduced by $50 \%$. Among the challenges facing this unit for better implementing this approach was an appropriate evaluation of nurse performance in each period.

\subsection{Nurses}

One of the significant challenges facing nurses before using the model was the dissatisfaction with assigned shifts and complaints about injustice. According to a survey of nurses after implementing the model, their satisfaction has been increased by $30 \%$. Furthermore, developing a transparent nurse scheduling system based on the performance evaluation increased nurses' motivation to achieve a higher rank at the end of each period. How to evaluate the performance and rank obtained by nurses, including their ambiguities and questions after implementing the model. To solving this problem, it was decided to provide more comprehensive information about the rank obtained by each nurse by the nursing unit for the following courses.

\subsection{Patients}

Patients are among the groups that are indirectly affected by nurse scheduling. Fair scheduling increases nurses' satisfaction and service quality. Although reports indicate fewer complaints in the given period, this approach's effect should be investigated in the long run.

\subsection{Physicians}

Physicians are among the category directly affected by the nurses' performance. Documenting patients' history, regular check-ups, and relevant reports are among the nurse rating criteria. Increased satisfaction of physicians was among other results of this study.

\subsection{Future works}

Also, future works can be considered below topics:

- Consider a mechanism to increase justice in work shifts (e.g., if the nurse's rights are lost in one period, in the period or periods to be compensated).

- Consider other goals such as reducing overtime, reducing costs based on different hospitals' policies.

- Generalization of the issue to other wards of the hospital and integrated schedule of all nurses.

- Use innovative and meta-heuristic algorithms to solve large-scale problems.

- Apply new policies in case of unplanned absences.

\section{REFERENCES}

[1] H. Aboutorab, M. Saberi, M.R. Asadabadi, O. Hussain and E. Chang, ZBWM: the Z-number extension of Best Worst Method and its application for supplier development. Expert Syst. App. 107 (2018) 115-125.

[2] W. Agyei, W. Obeng-Denteh and E.A. Andaam, Modeling nurse scheduling problem using 0-1 goal programming: a case study of Tafo Government Hospital, Kumasi-Ghana. Int. J. Sci. Technol. Res. 4 (2015) 5-10.

[3] L.H. Aiken, D.M. Sloane, J. Ball, L. Bruyneel, A.M. Rafferty and P. Griffiths, Patient satisfaction with hospital care and nurses in England: an observational study. BMJ Open 8 (2018) e019189.

[4] M. Alharbi, Nurse scheduling model in saudi arabia hospitals. Int. J. Comput. Digital Syst. 7 (2018) $103-109$.

[5] A. Amindoust, M. Asadpour and S. Shirmohammadi, A hybrid genetic algorithm for nurse scheduling problem considering the fatigue factor. J. Healthcare Eng. (2021). DOI: 10.1155/2021/5563651.

[6] M.P. Ariyani, C.N. Rosyidi and A. Aisyati, An optimization model of nurse scheduling using goal programming method: a case study. IOP Conf. Ser.: Mater. Sci. Eng. 1096 (2021) 12022.

[7] A. Azadeh and R. Kokabi, Z-number DEA: a new possibilistic DEA in the context of Z-numbers. Adv. Eng. Inf. 30 (2016) $604-617$. 
[8] E. Babaee Tirkolaee and N.S. Aydın, A sustainable medical waste collection and transportation model for pandemics. Waste Manage. Res. 39 (2021) 34-44.

[9] S. Blythe and J. E. Goodpasture, Nursing home fraud schemes: Forensic accounting lessons from litigation. Int. J. Healthc. Manag. 14 (2021) 91-98.

[10] R.L. Burdett and E. Kozan, An integrated approach for scheduling health care activities in a hospital. Eur. J. Oper. Res. 264 (2018) 756-773.

[11] E. Burke and E. Soubeiga, Scheduling nurses using a tabu-search hyperheuristic. In: Proceedings of the 1st Multidisciplinary International Conference on Scheduling: Theory and Applications (MISTA 2003), Nottingham, UK (2003) $180-197$.

[12] B. Chang, C.-W. Chang and C.-H. Wu, Fuzzy DEMATEL method for developing supplier selection criteria. Expert Syst. App. 38 (2011) $1850-1858$.

[13] A.A. Constantino, E. Tozzo, R.L. Pinheiro, D. Landa-Silva and W. Romão, A variable neighbourhood search for nurse scheduling with balanced preference satisfaction. In: ICEIS (2015) 462-470.

[14] J. den Bergh, J. Beliën, P. De Bruecker, E. Demeulemeester and L. De Boeck, Personnel scheduling: a literature review. Eur. J. Oper. Res. 226 (2013) 367-385.

[15] A. Dumrongsiri and P. Chongphaisal, Nurse scheduling in a hospital emergency department: a case study at a Thai University Hospital. Songklanakarin J. Sci. Technol. 40 (2018) 187-196.

[16] M. Ehrgott and X. Gandibleux, Multi-objective combinatorial optimization - theory, methodology, and applications. In: Multiple Criteria Optimization: State of the Art Annotated Bibliographic Surveys. Springer (2003) 369-444.

[17] A. M. Fathollahi-Fard, A. Ahmadi, F. Goodarzian and N. Cheikhrouhou, A bi-objective home healthcare routing and scheduling problem considering patients' satisfaction in a fuzzy environment. Appl. Soft Comput. 93 (2020) 106385.

[18] F. Goodarzian, A. Abraham and A. M. Fathollahi-Fard, A biobjective home health care logistics considering the working time and route balancing: a self-adaptive social engineering optimizer. J. Comput. Des. Eng. 8 (2021) $452-474$.

[19] H. Guo, J. Tang and G. Qu, Historical data-driven nurse flexible scheduling problem. In: 2013 25th Chinese Control and Decision Conference (CCDC) (2013) 1275-1280.

[20] R. Håkansson, Staff scheduling in elderly care: a simulation study of trade-offs. Dissertion (2015). http://urn.kb.se/resolve? urn=urn: nbn: se: liu:diva-115754.

[21] M. Hamid, R. Tavakkoli-Moghaddam, F. Golpaygani and B. Vahedi-Nouri, A multi-objective model for a nurse scheduling problem by emphasizing human factors. Proc. Inst. Mech. Eng. Part H: J. Eng. Med. 234 (2020) 179-199.

[22] R. Heiser, Using a best-practice perioperative governance structure to implement better block scheduling. AORN J. 97 (2013) $125-131$.

[23] Y.-C. Hu and P.-C. Liao, Finding critical criteria of evaluating electronic service quality of internet banking using fuzzy multiple-criteria decision making. Appl. Soft Comput. 11 (2011) 3764-3770.

[24] P.J.H. Hulshof, N. Kortbeek, R.J. Boucherie, E.W. Hans and P.J.M. Bakker, Taxonomic classification of planning decisions in health care: a structured review of the state of the art in OR/MS. Health Syst. 1 (2012) 129-175.

[25] C.-L. Hwang and K. Yoon, Methods for multiple attribute decision making. In: Multiple Attribute Decision Making. Springer (1981) 58-191.

[26] H. Jafari and H. Haleh, Nurse scheduling problem by considering fuzzy modeling approach to treat uncertainty on nurses' preferences for working shifts and weekends off. J. Optim. Ind. Eng. 14 (2021) 275-284.

[27] B. Kang, D. Wei, Y. Li and Y. Deng, A method of converting Z-number to classical fuzzy number. J. Inf. Comput. Sci. 9 (2012) 703-709.

[28] S.P. Keehan, D.A. Stone, J.A. Poisal, G.A. Cuckler, A.M. Sisko, S.D. Smith, A.J. Madison, C.J. Wolfe and J.M. Lizonitz, National health expenditure projections, 2016-25: price increases, aging push sector to 20 percent of economy. Health Affairs 36 (2017) 553-563.

[29] A. Legrain, J. Omer and S. Rosat, A rotation-based branch-and-price approach for the nurse scheduling problem. Math. Program. Comput. 12 (2020) 417-450.

[30] C.-C. Lin, J.-R. Kang, D.-J. Chiang and C.-L. Chen, Nurse scheduling with joint normalized shift and day-off preference satisfaction using a genetic algorithm with immigrant scheme. Int. J. Distrib. Sensor Netw. 11 (2015) 595419.

[31] B. Maenhout and M. Vanhoucke, An integrated nurse staffing and scheduling analysis for longer-term nursing staff allocation problems. Omega 41 (2013) 485-499.

[32] C. Maier-Rothe and H.B. Wolfe, Cyclical scheduling and allocation of nursing staff. Soc.-Econ. Plan. Sci. 7 (1973) $471-487$.

[33] R. Meghdad, R. Nayereh, S. Zahra, Z. Houriye and N. Reza, Assessment of the performance of nurses based on the 360-degree model and fuzzy multi-criteria decision-making method (FMCDM) and selecting qualified nurses. Heliyon 6 (2020) e03257.

[34] A. Mobasher, Nurse Scheduling Optimization in a General Clinic and An Operating Suite. University of Houston (2011).

[35] M. Mohammadian, M. Babaei, M. Amin Jarrahi and E. Anjomrouz, Scheduling nurse shifts using goal programming based on nurse preferences: a case study in an emergency department. Int. J. Eng. 32 (2019) 954-963.

[36] C.W. Mueller and J.C. McCloskey, Nurses' job satisfaction: a proposed measure. Nursing Res. 39 (1990) $113-117$.

[37] D.S.M. Nasir, N.H.C. Baharom, N.H. Shafii and N.A.M. Nor, Cyclical nurse scheduling in Shah Alam Hospital using goal programming. J. Comput. Res. Innov. 6 (2021) 1-10.

[38] J.H. Oldenkamp, Investigating reasoning in maternity-care scheduling. Knowl. Policy 5 (1992) 67-76.

[39] S.N.A. Razali, L.M. Fen, N. Arbin and A. Khamis, Integer linear programming on preference maximized of workforce scheduling. Compusoft 7 (2018) 2926-2930. 
[40] I. Rizany, R.T.S. Hariyati, E. Afifah and Rusdiyansyah, The impact of nurse scheduling management on nurses' job satisfaction in army hospital: a cross-sectional research. SAGE Open 9 (2019) 2158244019856189.

[41] T. Saaty, The Analytic Hierarchy Process (AHP) for Decision Making. Kobe, Japan (1980).

[42] J. Schoenfelder, K.M. Bretthauer, P.D. Wright and E. Coe, Nurse scheduling with quick-response methods: improving hospital performance, nurse workload, and patient experience. Eur. J. Oper. Res. 283 (2020) 390-403.

[43] T. Seyda and S. Hasan, Nurse scheduling using fuzzy modeling approach Fuzzy Sets and Systems. Oper. Res. 11 (2010) 1543-1563.

[44] S.P. Siferd and W.C. Benton, Workforce staffing and scheduling: hospital nursing specific models. Eur. J. Oper. Res. 60 (1992) 233-246.

[45] S. Simić, D. Milutinović, S. Sekulić, D. Simić, S.D. Simić and J. Dordević, A hybrid case-based reasoning approach to detecting the optimal solution in nurse scheduling problem. Logic J. IGPL 28 (2020) 226-238.

[46] A. Soroudi and T. Amraee, Decision making under uncertainty in energy systems: state of the art. Renew. Sustainable Energy Rev. 28 (2013) 376-384.

[47] A.C. Svirsko, B.A. Norman, D. Rausch and J. Woodring, Using mathematical modeling to improve the emergency department nurse-scheduling process. J. Emergency Nursing 45 (2019) 425-432.

[48] E.B. Tirkolaee, N.S. Aydın, M. Ranjbar-Bourani and G.W. Weber, A robust bi-objective mathematical model for disaster rescue units allocation and scheduling with learning effect. Comput. Ind. Eng. 149 (2020) 106790.

[49] E.B. Tirkolaee, A. Mardani, Z. Dashtian, M. Soltani and G.W. Weber, A novel hybrid method using fuzzy decision making and multi-objective programming for sustainable-reliable supplier selection in two-echelon supply chain design. J. Cleaner Prod. 250 (2020) 119517.

[50] A. Uhde, N. Schlicker, D.P. Wallach and M. Hassenzahl, Fairness and decision-making in collaborative shift scheduling systems. In: Proceedings of the 2020 CHI Conference on Human Factors in Computing Systems (2020) 1-13.

[51] Y. Yang and J. Wang, SMAA-based model for decision aiding using regret theory in discrete Z-number context. Appl. Soft Comput. 65 (2018) 590-602.

[52] L.A. Zadeh, A note on Z-numbers. Inf. Sci. 181 (2011) 2923-2932.

[53] S. Zanda, P. Zuddas and C. Seatzu, Long term nurse scheduling via a decision support system based on linear integer programming: a case study at the University Hospital in Cagliari. Comput. Ind. Eng. 126 (2018) 337-347.

[54] P. Zurn, C. Dolea and B. Stilwell, Nurse retention and recruitment: developing a motivated workforce. International Council of Nurses (2005).

\section{Subscribe to Open (S2O) A fair and sustainable open access model}

This journal is currently published in open access under a Subscribe-to-Open model (S2O). S2O is a transformative model that aims to move subscription journals to open access. Open access is the free, immediate, online availability of research articles combined with the rights to use these articles fully in the digital environment. We are thankful to our subscribers and sponsors for making it possible to publish this journal in open access, free of charge for authors.

\section{Please help to maintain this journal in open access!}

Check that your library subscribes to the journal, or make a personal donation to the $\mathrm{S} 2 \mathrm{O}$ programme, by contacting subscribers@edpsciences.org

More information, including a list of sponsors and a financial transparency report, available at: https://www. edpsciences.org/en/maths-s2o-programme 